\title{
Alkyl Levulinates from Furfuryl Alcohol Using CT151 Purolite as Heterogenous Catalyst: Optimization, Purification, and Recycling
}

\author{
Mattia Annatelli, Giacomo Trapasso, Lucrezia Lena and Fabio Aricò *
}

Citation: Annatelli, M.; Trapasso, G.; Lena, L.; Aricò, F. Alkyl Levulinates from Furfuryl Alcohol Using CT151 Purolite as Heterogenous Catalyst: Optimization, Purification, and Recycling. Sustain. Chem. 2021, 2, 493-505. https://doi.org/10.3390/ suschem 2030027

Academic Editor: Matthew Jones

Received: 24 May 2021

Accepted: 4 August 2021

Published: 13 August 2021

Publisher's Note: MDPI stays neutral with regard to jurisdictional claims in published maps and institutional affiliations.

Copyright: (c) 2021 by the authors. Licensee MDPI, Basel, Switzerland. This article is an open access article distributed under the terms and conditions of the Creative Commons Attribution (CC BY) license (https:// creativecommons.org/licenses/by/ $4.0 /)$.
Department of Environmental Sciences, Informatics and Statistics, Ca' Foscari University of Venice, 30172 Venezia, Italy; 843199@stud.unive.it (M.A.); 857194@stud.unive.it (G.T.); 858771@stud.unive.it (L.L.)

* Correspondence: fabio.arico@unive.it

Abstract: Commercially available Purolite CT151 demonstrated to be an efficient acid catalyst for the synthesis of alkyl levulinates via alcoholysis of furfuryl alcohol (FA) at mild temperatures $\left(80-120^{\circ} \mathrm{C}\right)$ and short reaction time $(5 \mathrm{~h})$. Reaction conditions were first optimized for the synthesis of ethyl levulinate and then tested for the preparation of methyl-, propyl-, isopropyl-, butyl, sec-butyl- and allyl levulinate. Preliminary scale-up tests were carried out for most of the alkyl levulinates (starting from $5.0 \mathrm{~g}$ of FA) and the resulting products were isolated as pure by distillation in good yields (up to 63\%). Furthermore, recycling experiments, conducted for the preparation of ethyl levulinate, showed that both the Purolite CT151 and the exceeding ethanol can be recovered and reused for four consecutive runs without any noticeable loss in the catalyst activity.

Keywords: alkyl levulinate; furfuryl alcohol; alcoholysis; purolite resin; heterogenous catalyst; biobased platform chemicals; biorefinery

\section{Introduction}

Alkyl levulinates (AlkLevs) are biobased chemicals that occupy a strategic role in biomass valorization as potential substitutes of several oil-based compounds [1,2]. Their applications in the fields of biofuels (additives), plasticizers, lubricants, flavoring agents, fragrances, and green solvents have been extensively investigated [3,4].

In particular, short-chain (C1-C4) AlkLevs, i.e., methyl (MetLev), ethyl (EtLev) and butyl levulinate (BuLev), showed great potential as oxygenated fuel additives for gasoline blends [5-7]. AlkLevs were also employed as green solvents either as such or as precursors of $\gamma$-valerolactone (GVL), a cyclic ester that has found interesting applications in perfume and food industries in addition to being exploited as solvent and fuel additive [8,9].

As depicted in Figure 1, several synthetic routes to AlkLevs are reported in the literature; raw biomass or monomers derived from biomass can be both used as starting materials. The related synthetic procedures are based on an alcoholysis reaction promoted by (Brønsted) acid catalyst where the product selectivity depends on the substrate used [4]. In fact, direct conversion of biomass such as cellulose leads to AlkLevs with low or moderate yields due to a combination of solubility issues and drastic conditions required for the depolymerization step [10]. In this view, starting from simple C6 carbohydrates such as D-Glucose or D-Fructose is more convenient, although once again this acid-catalyzed methodology suffers from some solubility issues and the need for relative high temperature $\left(120-200{ }^{\circ} \mathrm{C}\right)$ [11-21]. It should also be mentioned that, when D-Glucose is employed as substrate, an isomerization step is required, and this negatively affects the AlkLev yield. Furthermore, using simple carbohydrates as starting materials often resulted in the formation of a certain amount of humins due to the presence of 5-(hydroxymethyl) furfural (HMF) as reaction intermediate, a biobased platform chemical well known for its unstable nature. 
In contrast, conversion of levulinic acid (LA) into alkyl levulinates via esterification is a high yielding process; however, since LA is derived from biomass, (poly)saccharides would be preferable starting materials [22-24].

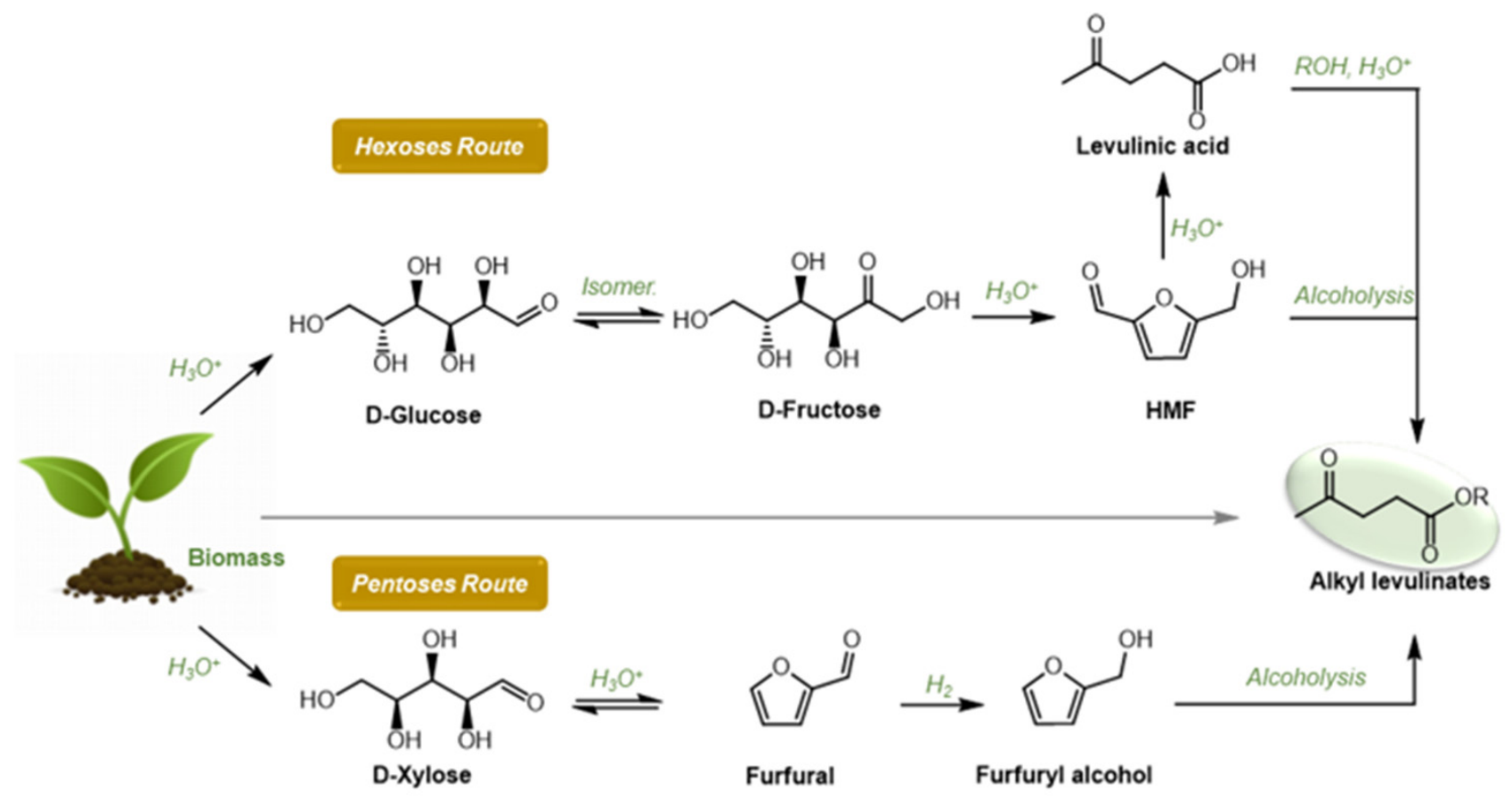

Figure 1. Hexoses and pentoses routed to alkyl levulinates.

Taking into account these considerations, a pentose sugar would be a more suitable starting material for AlkLev preparation (Figure 1). Pentose sugars such as D-xylose, obtained from hemicellulose, are easily converted into furfural via acid-catalyzed dehydration; furfural can then be promptly reduced to furfuryl alcohol (FA) via hydrogenation. As more than $60 \%$ of the furfural produced worldwide is transformed into FA, this precursor is low cost and available in large amounts. Together with LA, FA provides the most promising substrate for the preparation of AlkLevs [25].

Numerous acid catalysts were investigated for alcoholysis of FA to alkyl levulinates. Initial studies focused on the use of homogeneous catalysts such as strong mineral acids or metal salts. [26] However, the difficult product separation, catalyst toxicity, and reaction container corrosion led to the exploitation of heterogeneous catalysts, including acidic ion exchange resins [27-29], zeolites [30-32], (sulfated) zirconia-based catalysts [33-35], (supported) heteropolyacids [36-39], activated carbon [40-42], functionalized organosilica materials [43-48], ionic liquids [49,50], and several sulfonic acid functionalized materials [51-54]. Some studies were also conducted employing continuous-flow apparatus [32,44] or microwave-assisted procedures $[26,42]$. Despite this extensive research on the FA alcoholysis reaction, there are still some issues to be addressed in order to set up a cost-effective and green procedure for its conversion into AlkLevs. In fact, most of the abovementioned published works focused on the catalytic system highlighting its preparation, efficiency, and recycling. On the other hand, only limited attention was dedicated to the reaction scale since experiments are typically conducted starting from 1-10 mmol of FA (ca. 0.1-1.0 g). Furthermore, the purification of alkyl levulinates from the reaction mixture is never addressed in detail; FA conversion and AlkLevs yields are primarily determined employing various analytical methods, i.e., gas chromatography, gas chromatography-mass spectrometry, or high-performance liquid chromatography.

In this prospect, the work presented here encompasses a systematic study on the alcoholysis of FA to alkyl levulinates focusing on: 
- Efficiency of commercially available acid catalysts for the preparation of a library of AlkLevs that optimize the reaction conditions;

- Preliminary investigations on a larger scale reaction (up to $5.0 \mathrm{~g}$ of FA) to address the purification of AlkLevs;

- Recycling of the catalyst and of the reagent used in stoichiometric excess.

Results collected showed that, among the catalysts tested, Purolite CT151 was the most efficient for the synthesis of several alkyl levulinates in mild conditions. Methyl-, ethyl-, propyl-, isopropyl-, butyl-, sec-butyl-, and allyl levulinate were all prepared in good yields. The pure compounds were isolated as colorless or light yellowish liquids by distillation and fully characterized. Moreover, recycling experiments demonstrated that the Purolite CT151 can be reused for four runs without any noticeable loss in activity.

\section{Materials and Methods}

All reagents and solvents were purchased from Sigma-Aldrich; zeolite employed was also from Sigma-Merk (code: 96096). Purolites were kindly provided by Purolite ${ }^{\circledR}$. The reactions were monitored through GC-MS (GC System 6890N, Agilent Technologies mass selective detector 5973) with chromatography column HP-5MS. Compounds were injected with microsyringe Hamilton $(10 \mu \mathrm{L})$. NMR spectra were recorded with a Bruker $300 \mathrm{MHz}$ and $400 \mathrm{MHz}$ spectrometer, in $\mathrm{CDCl}_{3}$.

HR-MS spectra were acquired by means of a Bruker compact QTOF with a mass resolution of 30,000 in positive polarity mode. The mass calibration was conducted using a sodium formate cluster's solution and the data were processed in HPC mode. The acquisition was conducted in full scan mode in the range 50 to $500 \mathrm{~m} / \mathrm{z}$, with a $4.0 \mathrm{~L} \mathrm{~min}^{-1}$ at $180^{\circ} \mathrm{C}$ of source dry gas. The ion formula of each compound was calculated with the Smart formula tool within the Bruker software platform by using a $4 \mathrm{mDa}$ of mass confidence and considering the isotopic pattern ratio.

\subsection{General Synthetic Procedure for the Synthesis of Alkyl Levulinates in One Gram Scale}

In a $100 \mathrm{~mL}$ round bottom flask equipped with a water condenser and a magnetic stir bar, furfuryl alcohol $(1.0 \mathrm{~g}, 10.2 \mathrm{mmol})$ was dissolved in $20 \mathrm{~mL}$ of the corresponding alcohol in the presence of CT151 (0.5 g, 50\% wt.) as heterogeneous acid catalyst. The reaction mixture was heated at reflux temperature for $5 \mathrm{~h}$ under magnetic stirring. Afterward, the reaction was cooled to room temperature and the mixture was filtered on a layer of basic alumina and washed with a minimum amount of acetone. The solvent was evaporated by reduced pressure (rotavapor). The reaction crude was weighed ( $\mathrm{g}_{\text {crude }}$ ) and then analyzed via proton NMR. A comparison among NMR spectra of the pure samples (FA, EtLev, and EtMF) with the reaction mixture allowed the identification of residual traces of the reagent (FA), along with EtLev and EtMF. Integration of the distinctive NMR signals of these compounds gave the percent composition of the reaction mixture, i.e., \%FA, \%EtLev and $\%$ EtMF. Conversion was the \%FA observed. The yields of EtLev and EtMF were calculated considering the recovered amount of the reaction mixture ( $g_{\text {crude }}$ ) and the \%EtLev and \%EtMF evaluated via NMR. As an example, the yield of EtLev was assessed according to the equations $\mathrm{g}_{\text {EtLev }}=\%$ EtLev $\times \mathrm{g}_{\text {crude }}$ and thus Yield $\mathrm{EtLev}=\left(\mathrm{g}_{\mathrm{EtLev}} / \mathrm{g}_{\text {theorical }}\right) \times 100$. The same calculation allowed for achieving the EtMF yield (Tables 1-3).

\subsection{General Synthetic Procedure for the Synthesis of Alkyl Levulinates in Five Gram Scale}

In a $250 \mathrm{~mL}$ round bottom flask equipped with a water condenser and a magnetic stir bar, furfuryl alcohol $(5.0 \mathrm{~g}, 50.9 \mathrm{mmol})$ was dissolved in $100 \mathrm{~mL}$ of the corresponding alcohol in presence of CT151 (2.5 g, 50\% wt.) as heterogeneous acid catalyst. The reaction mixture was heated at solvent reflux temperature for $5 \mathrm{~h}$ under magnetic stirring. Afterwards, the reaction was cooled to room temperature and the mixture was filtered on a layer of basic alumina and washed with a minimum amount of acetone. The organic phase recovered was transferred (in two tranches) to a $100 \mathrm{~mL}$ double-necked round bottom flask equipped with distillation apparatus; the solvent was distilled at atmospheric pressure. In 
order to completely remove any solvent residue, the mixture was transferred into a $25 \mathrm{~mL}$ double-necked round bottom flask equipped with distillation apparatus connected to a vacuum pump (40-60 mbar). The alkyl levulinates were then purified through distillation at reduced pressure as transparent or light-yellow liquids (Table 4).

Ethyl levulinate (EtLev) was obtained as a transparent liquid in $63 \%$ yield $(4.6 \mathrm{~g}$, $32.11 \mathrm{mmol}) .{ }^{1} \mathrm{H}-\mathrm{NMR}\left(400 \mathrm{MHz}, \mathrm{CDCl}_{3}\right), \delta$ ppm: $1.26(\mathrm{t}, 3 \mathrm{H}) ; 2.20(\mathrm{~s}, 3 \mathrm{H}) ; 2.57(\mathrm{t}, 2 \mathrm{H}) ; 2.76$ (t, 2H); 4.14 (q, 2H). ${ }^{13} \mathrm{C}-\mathrm{HMR}\left(100 \mathrm{MHz}, \mathrm{CDCl}_{3}\right), \delta$, ppm: 14.15; 28.94; 31.82; 39.34; 59.01; 172.75; 201.97. Data are coherent with those previously reported in the literature [55].

Isopropyl levulinate (iPrLev) was obtained as a transparent liquid in 50\% yield (4.0 g, $25.47 \mathrm{mmol}) .{ }^{1} \mathrm{H}-\mathrm{NMR}\left(400 \mathrm{MHz}, \mathrm{CDCl}_{3}\right), \delta$, ppm: $1.25(\mathrm{~d}, 6 \mathrm{H}) ; 2.21(\mathrm{~s}, 3 \mathrm{H}) ; 2.56(\mathrm{t}, 2 \mathrm{H})$; $2.76(\mathrm{t}, 2 \mathrm{H}) ; 5.01(\mathrm{~m}, 1 \mathrm{H}) .{ }^{13} \mathrm{C}-\mathrm{HMR}\left(100 \mathrm{MHz}, \mathrm{CDCl}_{3}\right), \delta$, ppm: 21.78; 28.39; 29.89; 38.02; $67.99 ; 175.34 ; 201.84$. Data are coherent with those previously reported in the literature [56].

Butyl levulinate (BuLev) was obtained as a light-yellow liquid in $40 \%$ yield (3.51 g, $20.38 \mathrm{mmol}) .{ }^{1} \mathrm{H}-\mathrm{NMR}\left(400 \mathrm{MHz}, \mathrm{CDCl}_{3}\right), \delta$, ppm: $0.94(\mathrm{t}, 3 \mathrm{H}) ; 1.39(\mathrm{~m}, 2 \mathrm{H}) ; 1.62(\mathrm{~m}, 2 \mathrm{H})$; $2.20(\mathrm{~s}, 3 \mathrm{H}) ; 2.58(\mathrm{t}, 2 \mathrm{H}) ; 2.76(\mathrm{t}, 2 \mathrm{H}) ; 4.09(\mathrm{t}, 2 \mathrm{H}) .{ }^{13} \mathrm{C}-\mathrm{HMR}\left(100 \mathrm{MHz}, \mathrm{CDCl}_{3}\right), \delta, \mathrm{ppm}$ : $14.53 ; 20.02 ; 27.55 ; 29.86 ; 33.05 ; 37.97 ; 62.41 ; 171.80 ; 207.34$. HRMS: $\mathrm{m} / \mathrm{z}[\mathrm{M}+\mathrm{Na}]^{+}$calc. for $\left[\mathrm{C}_{9} \mathrm{H}_{16} \mathrm{O}_{3}+\mathrm{Na}\right]^{+}:$195.0992; found: 195.0983 .

sec-Butyl levulinate (sBuLev) was purified via vacuum distillation obtaining a lightyellow liquid with a yield of 30\% (2.63 g $15.27 \mathrm{mmol}) .{ }^{1} \mathrm{H}-\mathrm{NMR}\left(400 \mathrm{MHz}, \mathrm{CDCl}_{3}\right), \delta, \mathrm{ppm}$ : $0.90(\mathrm{t}, 3 \mathrm{H}) ; 1.21(\mathrm{~d}, 3 \mathrm{H}) ; 1.57(\mathrm{~m}, 2 \mathrm{H}) ; 2.20(\mathrm{~s}, 3 \mathrm{H}) ; 2.57(\mathrm{t}, 2 \mathrm{H}) ; 2.75(\mathrm{t}, 2 \mathrm{H}) ; 4.85(\mathrm{~m}, 1 \mathrm{H})$. ${ }^{13} \mathrm{C}-\mathrm{HMR}\left(100 \mathrm{MHz}, \mathrm{CDCl}_{3}\right), \delta$, ppm: 9.63; 19.39; 28.35; 28.77; 32.53; 38.04; 72.90; 174.46; 205.55. Data are coherent with those previously reported in the literature [56].

Allyl levulinate (AllLev) was obtained as light-yellow liquid in 55\% yield (4.38 g, $28.04 \mathrm{mmol}) .{ }^{1} \mathrm{H}-\mathrm{NMR}\left(400 \mathrm{MHz}, \mathrm{CDCl}_{3}\right), \delta$, ppm: $2.21(\mathrm{~s}, 3 \mathrm{H}) ; 2.63(\mathrm{t}, 2 \mathrm{H}) ; 2.78(\mathrm{t}, 2 \mathrm{H})$; $4.61(\mathrm{~d}, 2 \mathrm{H}) ; 5.31(\mathrm{~m}, 2 \mathrm{H}) ; 5.94(\mathrm{~m}, 1 \mathrm{H}) .{ }^{13} \mathrm{C}-\mathrm{HMR}\left(100 \mathrm{MHz}, \mathrm{CDCl}_{3}\right), \delta$, ppm: 27.53; 29.86; 37.91; 64.64; 118.25; 131,34; 172.41; 205.74. HRMS: $\mathrm{m} / \mathrm{z}[\mathrm{M}+\mathrm{Na}]^{+}$calc. for $\left[\mathrm{C}_{8} \mathrm{H}_{12} \mathrm{O}_{3}+\mathrm{Na}\right]^{+}$: 179.0679; found: 179.0676 .

Synthesis of methyl levulinate in autoclave: Furfuryl alcohol (5.00 g, $50.97 \mathrm{mmol})$ was dissolved in $100 \mathrm{~mL}$ of methanol in the presence of CT151 (2.50 g, 50\% wt.) as heterogeneous acid catalyst. The reaction mixture was heated at $80^{\circ} \mathrm{C}$ for $5 \mathrm{~h}$ with an autogenous pressure of 2 bar. The purification proceeds by distillation as previously reported.

Methyl levulinate (MeLev) was obtained as a transparent liquid with a yield of 55\% (3.65 g, $28.05 \mathrm{mmol}) .{ }^{1} \mathrm{H}-\mathrm{NMR}\left(400 \mathrm{MHz}, \mathrm{CDCl}_{3}\right), \delta, \mathrm{ppm}: 2.20(\mathrm{~s}, 3 \mathrm{H}) ; 2.58(\mathrm{t}, 2 \mathrm{H}) ; 2.76$ $(\mathrm{t}, 2 \mathrm{H}) ; 3.68$ (s, 3H). ${ }^{13} \mathrm{C}-\mathrm{HMR}\left(100 \mathrm{MHz} \mathrm{CDCl}_{3}\right), \delta, \mathrm{ppm}: 27.73 ; 29.84 ; 37,94 ; 51.77 ; 173.20$; 206.58. Data are coherent with those previously reported in the literature [57].

\section{Results and Discussion}

\subsection{Ethyl Levulinate as Model Study: Optimization of the Reaction Conditions}

Ethyl levulinate (EtLev) was selected as a model compound to test the efficiency of the heterogenous and homogeneous catalysts for the alcoholysis of furfuryl alcohol (Scheme 1, Table 1).

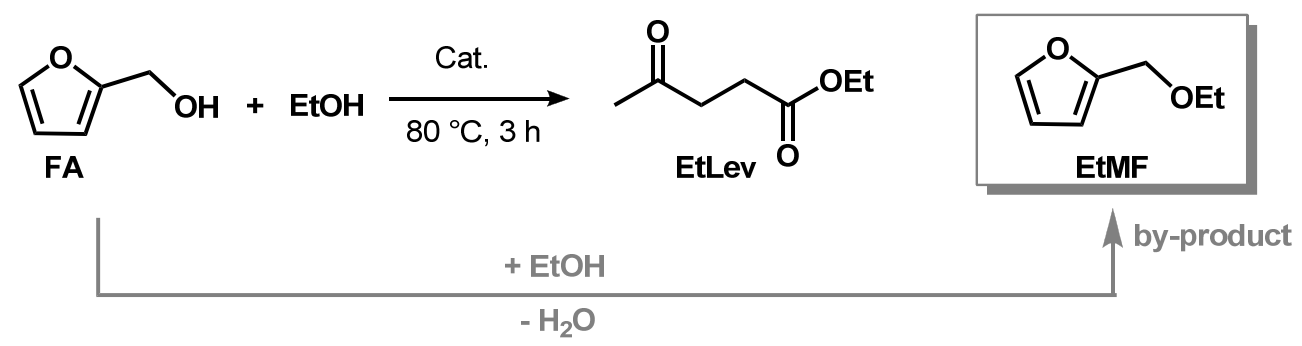

Scheme 1. Synthesis of ethyl levulinate in presence of an acid catalyst. 
Table 1. Synthesis of EtLev in presence of heterogenous and homogenous acid catalysts ${ }^{\text {a }}$.

\begin{tabular}{|c|c|c|c|c|c|}
\hline & \multirow{2}{*}{$\#$} & \multirow{2}{*}{ Catalyst } & \multirow{2}{*}{$\begin{array}{c}\text { Conv. } \\
(\%)\end{array}$} & \multicolumn{2}{|c|}{${ }^{1}$ H-NMR Yield } \\
\hline & & & & EtLev (\%) & EtMF (\%) \\
\hline \multirow{10}{*}{$\begin{array}{l}\text { Heterogeneous } \\
\quad(10 \% \text { wt. })\end{array}$} & 1 & - & 0 & 0 & 0 \\
\hline & 2 & Amberlyst- $15^{b}$ & 100 & 22 & 16 \\
\hline & 3 & CT275 & 48 & 8 & 11 \\
\hline & 4 & $\mathrm{CT} 275^{\mathrm{b}}$ & 100 & 27 & 12 \\
\hline & 5 & СТ269 & 64 & 11 & 17 \\
\hline & 6 & $\mathrm{CT} 269^{\mathrm{b}}$ & 100 & 25 & 14 \\
\hline & 7 & CT151 & 44 & 14 & 12 \\
\hline & 8 & CT151 b & 100 & 34 & 15 \\
\hline & 9 & Al-Hd & 0 & 0 & 0 \\
\hline & 10 & Zeolite $^{\mathrm{c}}$ & 0 & 0 & 0 \\
\hline \multirow{6}{*}{$\begin{array}{l}\text { Homogeneous } \\
\text { (10\% mol.) }\end{array}$} & 11 & $\mathrm{AlCl}_{3}$ & 94 & 40 & 8 \\
\hline & 12 & $\mathrm{H}_{2} \mathrm{SO}_{4}$ & 100 & 52 & 0 \\
\hline & 13 & $\mathrm{CH}_{3} \mathrm{COOH}$ & 0 & 0 & 0 \\
\hline & 14 & $\mathrm{CF}_{3} \mathrm{COOH}$ & 10 & 5 & 0 \\
\hline & 15 & $\mathrm{BF}_{3}-\mathrm{O}(\mathrm{Et})_{2}$ & 100 & 10 & 0 \\
\hline & 16 & $(\mathrm{COOH})_{2}$ & 0 & 0 & 0 \\
\hline
\end{tabular}

${ }^{a}$ Reaction conditions: FA $(1.0 \mathrm{~g}, 10.19 \mathrm{mmol})$ in ethanol $(20.0 \mathrm{~mL})$ at $80^{\circ} \mathrm{C}$ for $3 \mathrm{~h} .{ }^{\mathrm{b}}$ Dried in oven at $100{ }^{\circ} \mathrm{C}$ ${ }^{\mathrm{c}}$ calcinated at $400{ }^{\circ} \mathrm{C}$ overnight.

In a typical experiment, FA was reacted with an excess of ethanol, used as solvent and reagent, in the presence of an acid catalyst. The reaction was conducted under magnetic stirring at reflux temperature $\left(80{ }^{\circ} \mathrm{C}\right)$ for $3 \mathrm{~h}$. Thus, prior to solvent evaporation, the mixture was filtered on a thin layer of basic alumina to remove acid residues that in some cases led to the formation of insoluble black plastic material (Supplementary Figure S1). The product yield was calculated via proton NMR (see Materials and Methods), as this technique allowed for certain identification of the signals related to furfuryl alcohol, ethyl levulinate, and 2-(ethoxymethyl)furan (EtMF) that forms as reaction intermediate.

The first test was conducted in the absence of a catalyst (\#1; Table 1); FA was recovered unaltered from the reaction mixture. Amberlyst-15 was used as referring catalyst (\#2; Table 1) as it has been extensively investigated for the alcoholysis of furfuryl alcohol $[29,30]$. In our reaction conditions, Amberlyst-15 led to a quantitative conversion of FA; however, EtLev formed only in $22 \%$ yield.

Purolite exchange resins, available in our laboratory, were then tested (\#3-8; Table 1). Purolites are polystyrenic strong acid cation resins with different potential applications. Three different Purolite types were investigated, all incorporating sulfonic groups (Supplementary Table S1):

- Purolite CT275, a macroporous catalyst showing excellent accessibility of active sites;

- Purolite CT269, a macroporous catalyst with very good mechanical resistance;

- Purolite CT151, a macroporous polystyrene crosslinked with divinylbenzene.

The Purolites selected were employed both wet and after being oven dried at $100{ }^{\circ} \mathrm{C}$ overnight (\#3-8; Table 1). The presence of interstitial water in these sulfonated resins resulted in a lower efficiency with discrete values of FA conversion and product yield; in contrast, dried Purolites led to more promising results as EtLev yields ranged from 25 to $34 \%$.

Acid-alumina (Al-H) and zeolite were also tested, after calcination at $400{ }^{\circ} \mathrm{C}$ overnight; in both cases FA conversion was negligible (\#9-10; Table 1).

Some homogeneous acid catalysts were investigated (\#11-16; Table 1). Experiments conducted in the presence of $\mathrm{AlCl}_{3}$ and $\mathrm{H}_{2} \mathrm{SO}_{4}$ allowed quantitative conversion of FA and discrete EtLev yield. However, these catalysts were discarded in consideration of their well-known toxicity/corrosivity, and foremost due to the formation of an insoluble 
black plastic material at the end of the reactions as consequence of the abovementioned concurrent polymerization reactions taking place in strong acidic conditions.

Despite the higher acidity of trifluoroacetic acid compared to acetic acid, both these homogeneous catalysts showed a negligible efficiency in promoting EtLev formation (\#13-14; Table 1). Similar discouraging results were achieved for the experiments conducted in the presence of oxalic acid and $\mathrm{BF}_{3}-\mathrm{O}(\mathrm{Et})_{2}(\# 15-16$, Table 1); the latter showing quantitative conversion but only limited yield.

In conclusion, although all Purolites displayed similar catalytic performances, the oven dried Purolite CT151 showed the best result (\#8; Table 1) and was selected for further optimization studies. Its observed enhanced efficiency might be ascribed to the smaller surface area and pore volume of Purolite CT151 compared to the other heterogenous catalysts employed (Supplementary Table S1); these characteristics might allow an optimal interaction with FA.

The effect of the amount of catalyst was next investigated; experiments were conducted by varying the amount of Purolite CT151 (Table 2). Amberlyst-15 was also tested in the same conditions as referring catalyst (\#1-8; Table 2).

Table 2. Synthesis of EtLev in presence of different amount of Purolite CT151 and Amberlyst-15 a .

\begin{tabular}{|c|c|c|c|c|}
\hline & \multirow{2}{*}{$\#$} & \multirow{2}{*}{ Amount Cat. } & \multicolumn{2}{|c|}{${ }^{1}$ H-NMR Yield } \\
\hline & & & EtLev (\%) & EtMF (\%) \\
\hline \multirow{4}{*}{ Amberlyst-15 ${ }^{b}$} & 1 & $10 \%$ wt. & 22 & 16 \\
\hline & 2 & $25 \%$ wt. & 37 & 5 \\
\hline & 3 & $50 \%$ wt. & 57 & 0 \\
\hline & 4 & $100 \%$ wt. & 63 & 0 \\
\hline \multirow{4}{*}{ CT151 ${ }^{b}$} & 5 & $10 \%$ wt. & 34 & 15 \\
\hline & 6 & $25 \%$ wt. & 50 & 3 \\
\hline & 7 & $50 \%$ wt. & 63 & 0 \\
\hline & 8 & $100 \%$ wt. & 72 & 0 \\
\hline
\end{tabular}

In all experiments, Purolite CT151 confirmed its superior catalytic activity compared to Amberlyst-15 and the latter was no further investigated in the present study.

Although the best results for the Purolite catalyst were obtained when used in 100\% wt., the difference in EtLev yield between the reaction conducted with 50\% wt. catalyst was too small to justify doubling the amount of catalyst. Thus, further optimization reactions were conducted in the presence of 50\% wt. Purolite CT151.

Several experiments were carried out varying the reaction time; FA ethanolysis was carried out for 1, 2, 3, 5, and $7 \mathrm{~h}$ after the reaction mixture reached the operating temperature of $80^{\circ} \mathrm{C}$; the results achieved are depicted in Figure 2.

FA conversion reached quantitative value already after $2 \mathrm{~h}$ at reflux temperature; however, EtLev yield continued to increase, reaching a maximum at $5 \mathrm{~h}(71 \%)$. This discrepancy might be attributed to the formation of at least one reaction intermediate different from EtMF that was clearly visible in the proton NMR spectrum, although we were not able to identify or isolate it. When the reaction was prolonged to $7 \mathrm{~h}$, a lower yield of EtLev was observed (62\%), possibly due to concurrent side reactions and/or product degradation.

To validate the data so far achieved, a larger scale reaction was conducted on $5.0 \mathrm{~g}$ of FA; the experiment led to a slightly higher EtLev yield (77\% yield) compared to the one achieved on a $1.0 \mathrm{~g}$ scale. This result is a good indication that higher scale reactions might perform even better than smaller scale reactions. 


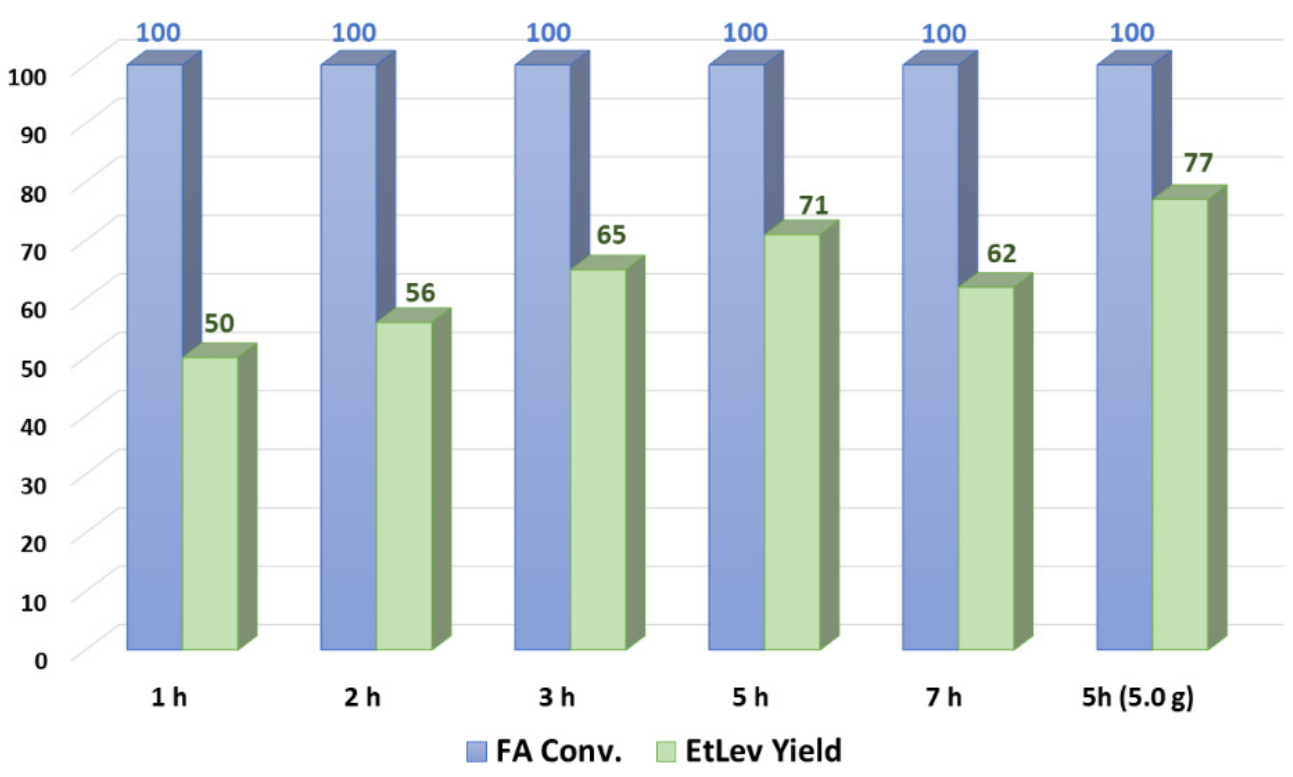

Figure 2. Synthesis of ethyl levulinate over time.

Figure 3 reports a possible reaction mechanism for the formation of EtLev from FA. A comprehensive investigation on the alcoholysis of furfuryl alcohol is still lacking, most likely due to the difficulties in identifying all the concurrent synthetic pathways and the related reaction intermediates; thus, further investigations are needed to clarify these aspects.

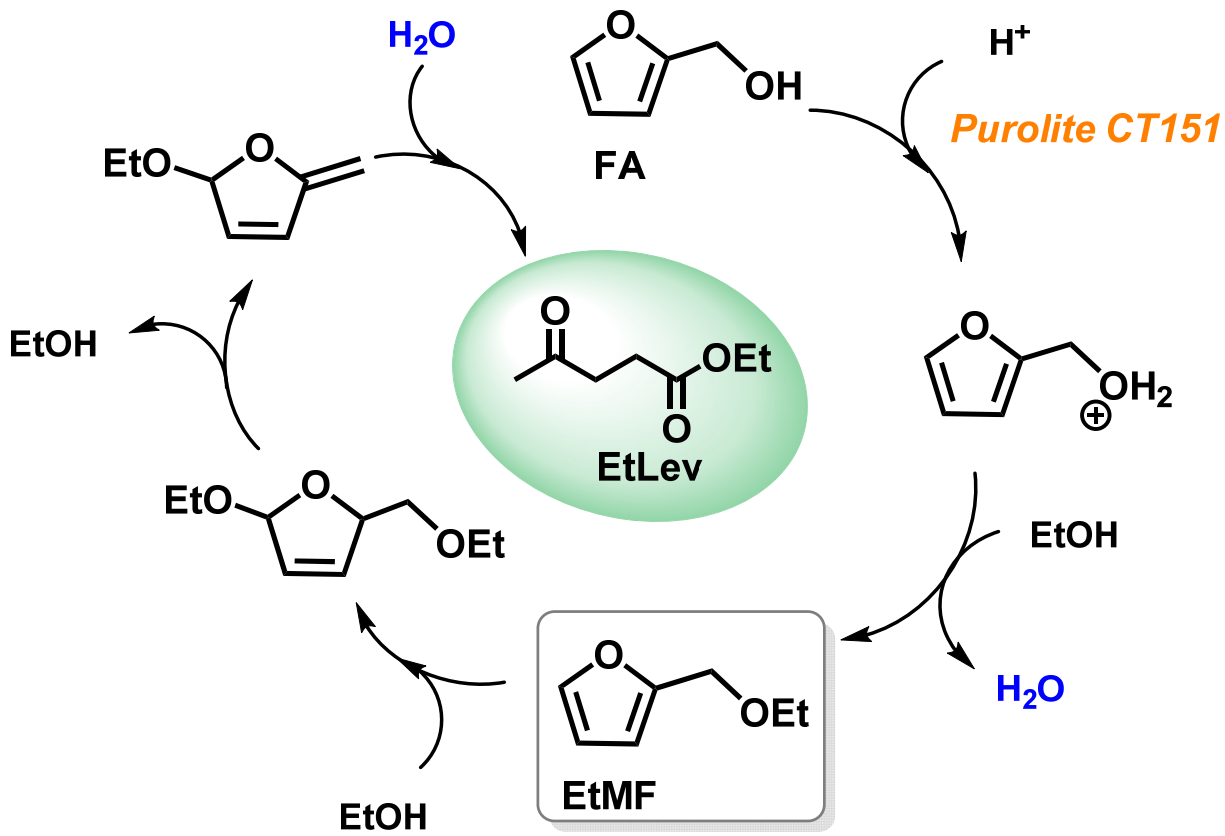

Figure 3. Proposed reaction mechanism for the alcoholysis of FA.

Additional optimization attempts were conducted by varying the operating temperature and the FA concentration, which was previously set arbitrarily at $0.50 \mathrm{M}(1.0 \mathrm{gr}$ in $20 \mathrm{~mL}$ of $\mathrm{EtOH})$. The reaction carried out at lower temperatures, i.e., from room temperature up to $60{ }^{\circ} \mathrm{C}$, led to reduced substrate conversion and lower EtLev yield (Supplementary Table S2). Similarly, when the FA ethanolysis was conducted on more diluted (0.25 M FA) or more concentrated (1.0 and 2.0 M) solutions, EtLev formed in lower yields (Supplementary Table S3). It can be assumed that at high dilution there is a reduced 
interaction between FA and ethanol. Meanwhile, working at high concentration, although faster interactions between the reagents took place, unwanted secondary reactions such as polymerization and degradation might also occur more rapidly, affecting product yield.

In conclusion, optimization investigations indicated that the best reaction condition encompassed a $0.5 \mathrm{M}$ solution of FA in ethanol heated at reflux temperature $\left(80^{\circ} \mathrm{C}\right)$ for $5 \mathrm{~h}$; analysis of the reaction mixture indicated an EtLev yield of $71 \%$ (77\% in larger scale).

\subsection{Alkyl Levulinates Syntheses, Products Isolation, and Catalyst Recycling}

With the best-found reaction conditions known, the scope of this procedure was next investigated to develop a library of alkyl levulinates. Thus, FA alcoholysis was conducted in the presence of primary (methanol, 1-propanol, 1-butanol), secondary (2-propanol, 2-butanol), and unsaturated (allyl alcohol) alcohol (Scheme 2, Table 3).

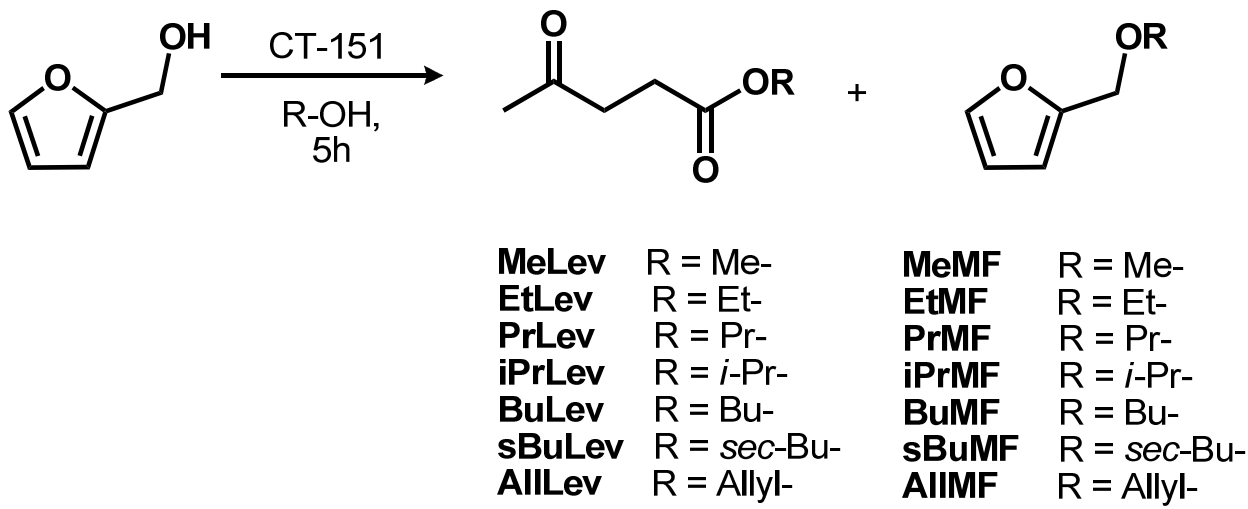

Scheme 2. Synthesis of alkyl levulinates in presence of acid catalyst Purolite CT151.

Table 3. Synthesis of alkyl levulinates ${ }^{a}$.

\begin{tabular}{cccccc}
\hline$\#$ & ROH & Purolite CT151 & Temp. $\left({ }^{\circ} \mathbf{C}\right)$ & \multicolumn{2}{c}{ AlkLev Yield (\%) } \\
\hline 1 & $\mathrm{MeOH}$ & $50 \% \mathrm{wt}$ & 80 & MeLev & 30 \\
$2^{\mathrm{b}}$ & $\mathrm{MeOH}$ & $50 \% \mathrm{wt}$ & 80 & MeLev & 50 \\
$3^{\mathrm{b}}$ & $\mathrm{MeOH}$ & $50 \% \mathrm{wt}$ & 160 & MeLev & 32 \\
$4^{5}$ & $\mathrm{EtOH}$ & $50 \% \mathrm{wt}$ & 80 & EtLev & 71 \\
5 & $\mathrm{PrOH}$ & $50 \% \mathrm{wt}$ & 80 & PrLev & 46 \\
$6^{7}$ & $\mathrm{PrOH}$ & $50 \% \mathrm{wt}$ & 100 & PrLev & 63 \\
$8^{2}$ & $\mathrm{PrOH}$ & $50 \% \mathrm{wt}$ & 80 & iPrLev & 60 \\
9 & $\mathrm{BuOH}$ & $50 \% \mathrm{wt}$ & 80 & BuLev & 44 \\
10 & $\mathrm{BuOH}$ & $50 \% \mathrm{wt}$ & 120 & BuLev & 55 \\
11 & secBuOH & $50 \% \mathrm{wt}$ & 80 & sBuLev & 33 \\
12 & secBuOH & $50 \% \mathrm{wt}$ & 100 & sBuLev & 40 \\
13 & $\mathrm{AllylOH}$ & $50 \% \mathrm{wt}$ & 80 & AllLev & 52 \\
& $\mathrm{AllylOH}$ & $50 \% \mathrm{wt}$ & 100 & AllLev & 62 \\
\hline
\end{tabular}

a Reaction conditions: FA $(1.0 \mathrm{~g}, 10.19 \mathrm{mmol}), \mathrm{ROH}(20 \mathrm{~mL})$ at the selected temperature for $5 \mathrm{~h} ; 100 \%$ conversion of FA was observed in all experiments. Yield was evaluated via ${ }^{1} \mathrm{H} \mathrm{NMR} ;{ }^{\mathrm{b}} \mathrm{FA}(2.0 \mathrm{~g}, 20.38 \mathrm{mmol}), \mathrm{MeOH}(40 \mathrm{~mL})$, $5 \mathrm{~h}$ in autoclave.

As reported in Table 3, AlkLevs were achieved in yields ranging from $30 \%$ up to $71 \%$ according to ${ }^{1} \mathrm{H}$ NMR data. Among them, methyl levulinate (MeLev) was the only product formed in a rather low yield (\#1, Table 3). Thus, an additional experiment was carried out in an autoclave apparatus at $80^{\circ} \mathrm{C}$, doubling the amount of the reagents and catalyst (\#2, Table 3). In these conditions an autogenous pressure of 2 bar was observed, which eventually favored the FA methanolysis reaction, leading to $50 \%$ yield of MeLev. A further autoclave test was conducted at $160{ }^{\circ} \mathrm{C}(\# 3$, Table 3); in this case the autogenous pressure increased constantly during the reaction up to 44 bar due to the unwanted formation of dimethyl ether. MeLev yield was calculated to be $32 \%$; most likely the reduced yield observed is imputable to degradation of the substrate at this high temperature. 
FA alcoholysis in the presence of the other selected alcohols was tested both at $80{ }^{\circ} \mathrm{C}$, and at their reflux temperature (\#5-13, Table 3). The latter experiments resulted in the formation of the related AlkLevs in higher yields (40-63\%).

Note also that to be best of our knowledge, this is the first time that allyl levulinate (AllLev, \#12-13, Table 3) was prepared via FA alcoholysis. Previous published reports focused mainly on levulinic acid esterification [58].

AllLev is an interesting derivative as the presence of the allyl group within the levulinate backbone can allow further chemical modification of this compound.

Having established the robustness of our procedure, the best experiments-for most of the AlkLevs reported in Table 3-were repeated in larger scale starting from $5.0 \mathrm{~g}$ of FA (Table 4) to address isolation of the products from the reaction mixture.

Table 4. Synthesis of alkyl levulinates ${ }^{\mathrm{a}}$.

\begin{tabular}{cccccc}
\hline$\#$ & ROH & Temp. $\left({ }^{\circ} \mathbf{C}\right)$ & AlkLev Yield $(\%)$ & Isolated Yield (\%) \\
\hline $1^{\mathrm{d}}$ & $\mathrm{MeOH}$ & 80 & MeLev & 65 & 55 \\
2 & EtOH & 80 & EtLev & 77 & 63 \\
3 & $i$ PrOH & 80 & iPrLev & 60 & 50 \\
4 & $\mathrm{BuOH}$ & 120 & BuLev & 55 & 44 \\
5 & secBuOH & 100 & sBuLev & 40 & 30 \\
6 & AllylOH & 100 & AllLev & 62 & 55 \\
\hline
\end{tabular}

a Reaction conditions: FA $(5.0 \mathrm{~g}, 50.97 \mathrm{mmol}), \mathrm{ROH}(100 \mathrm{~mL}), \mathrm{CT} 151(50 \% \mathrm{wt}$ ) $)$ reaction time $5 \mathrm{~h}$, quantitative conversion of FA was observed. ${ }^{b}$ Yield calculated via ${ }^{1} \mathrm{H}-\mathrm{NMR} ;{ }^{\mathrm{c}}$ Isolated yield by distillation. d $\mathrm{FA}(5.0 \mathrm{~g}$, $50.97 \mathrm{mmol}), \mathrm{MeOH}(100 \mathrm{~mL}), \mathrm{CT} 151\left(50 \% \mathrm{wt}\right.$.) at $80{ }^{\circ} \mathrm{C}$ for $5 \mathrm{~h}$ in autoclave, quantitative conversion of $\mathrm{FA}$ was observed.

After several attempts, we found that the best purification procedure encompassed the filtration of reaction mixture through a thin layer of basic alumina followed by a two-step distillation: (i) a first at atmospheric pressure to recover the residual alcohol, followed by (ii) a second distillation at reduced pressure to recover the pure AlkLev.

As shown in Table 4, the isolated yields of MeLev, EtLev, iPrLev, BuLev, sBuLev, and AllLev are fully consistent with the related values calculated by proton NMR analysis, confirming the validity of the analytical method used. It is interesting to point out that when the methanolysis of FA was conducted in larger scale, MeLev was achieved in higher yield $(65 \%)$ compared to the $2.0 \mathrm{~g}$ scale procedure $(50 \%)$, similar to that previously observed for the preparation of EtLev (Figure 2).

All AlkLevs were isolated as transparent or yellowish liquid and completely characterized to confirm the proposed structures (see Supplemental Materials).

Furthermore, as part of this investigation, catalyst recycling was also studied, focusing on the case of EtLev preparation.

Purolite CT151, a heterogeneous catalyst, can be recovered from the reaction mixture by simple filtration; however, due to magnetic stirring employed to ensure the reaction mixture homogeneity, the tiny catalyst spheres were reduced to powder. To solve this issue, the ethanolysis of FA was performed without stirring, although the EtLev yield decreased to $23 \%$. Further attempts were carried out inserting nitrogen flow via a glass pipette directly into the reaction mixture to ensure the mixing of the solution. Although in this case EtLev yield improved to $57 \%$, the continuous nitrogen inlet caused a rapid ethanol evaporation that had to be constantly added to the reaction mixture. In contrast, when a 100\% wt. of Purolite CT151 (compared to FA) was employed without stirring and/or nitrogen flow, EtLev was achieved with a yield comparable to our previous results, i.e., $66 \%$ (Supplementary Table S4).

Thus, the experiments on catalyst recycling were conducted employing FA:Purolite CT1515 in 1:1 weight ratio. At the end of each run, the catalyst was recovered, washed with the minimal amount of acetone, and dried overnight at $100{ }^{\circ} \mathrm{C}$. According to the data collected (Figure 4a) the catalyst can be reused for a maximum of four consecutive reactions; in fact, in the fifth run an evident decrease of EtLev yield was observed (44\%). 
Restoration of the catalyst acid sites was attempted by immersion of the spheres in an acid solution of water/methanol; the Purolite was then washed with acetone and dried overnight before being used in a new reaction. However, analysis of the reaction mixture showed that catalyst activity was not reestablished as EtLev yield was even lower than the fifth run (32\%). This result was ascribed to the surface poisoning of the catalyst due to deposition of carbonaceous material and polymers that formed during the degradation of furfuryl alcohol. In fact, as the recycling runs proceeded, the Purolite spheres assumed a dark black color consistent with the one of the degradation products (polymers and humins) previously observed.

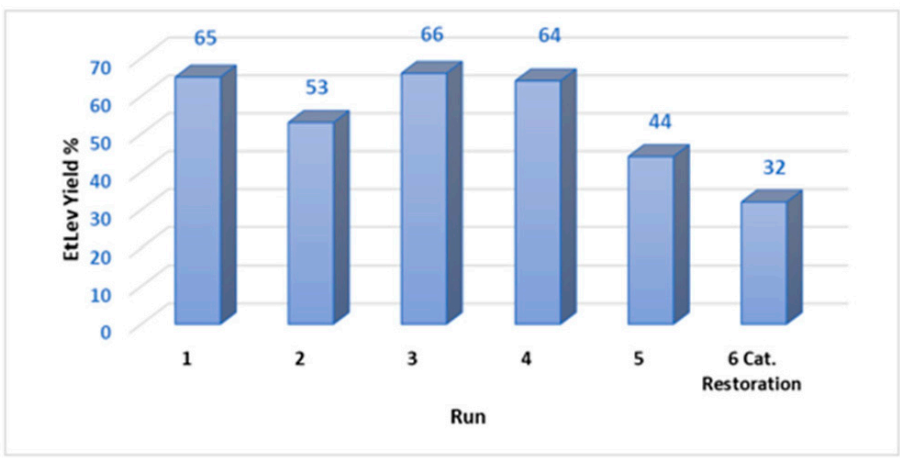

(a)

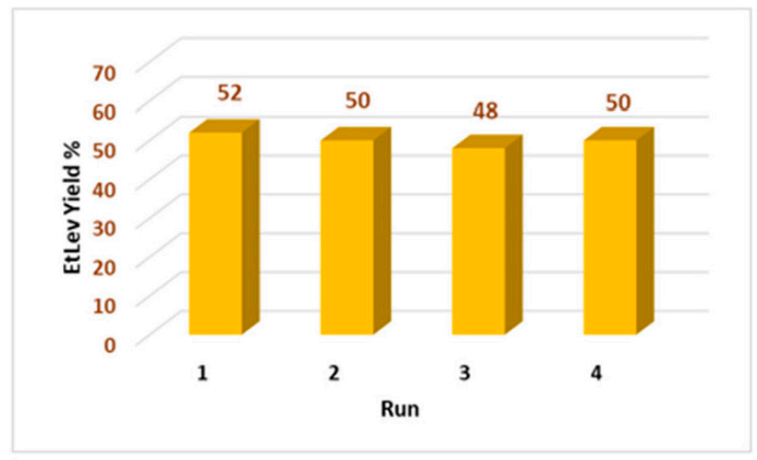

(b)

Figure 4. (a) Recycling of the catalyst Purolite CT151; FA (1.0 g, $10.19 \mathrm{mmol})$, EtOH (20 mL), Purolite CT1515 (100\% wt.) at $80{ }^{\circ} \mathrm{C}$ for $5 \mathrm{~h}$. (b) Recycling of the catalyst Purolite CT151 and of the exceeding ethanol; FA (5.0 g, $\left.50.9 \mathrm{mmol}\right), \mathrm{EtOH}$ (100 mL), Purolite CT1515 (100\% wt.) at $80^{\circ} \mathrm{C}$ for $5 \mathrm{~h}$.

At an industrial level, catalyst recycling is as relevant as the recovery and reuse of the reagents/solvents used in stoichiometric excess. Thus, some recycling tests were conducted on the five-gram-scale FA ethanolysis; both the catalyst and the exceeding ethanol were recycled for four consecutive runs (Figure $4 \mathrm{~b}$ ). For each recycling test the catalyst was recovered by filtration; the ethanol was recovered by distillation at atmospheric pressure and the product and EtLev purified via distillation at reduced pressure, as previously described. Ethanol distillation was operated in the presence of a mild flow of nitrogen to speed the procedure, although this caused a loss of about $30 \%(30 \mathrm{~mL})$ of the reagent that, in the following run, had to be replenished with new reagent.

As a result, the large-scale reaction for the ethanolysis of FA allowed isolation of pure EtLev with a constant yield of ca. 50\% in four consecutive runs where both ethanol and Purolite were recovered and reused (Figure 4b).

\section{Conclusions}

This work focuses on different aspects inherent to biomass valorization. Our intent was to fully investigate the process for the alcoholysis of furfuryl alcohol, starting from the selection of an efficient commercially available and low-cost homogenous/heterogenous acid catalyst, optimizing the reaction conditions, and exploring the scope of the reaction on different alcohols to achieve a library of alkyl levulinates isolated as pure compounds.

In this view, Purolite CT151-used in 50\% wt. compared to FA-demonstrated to be an effective catalyst for the preparation of methyl, ethyl-, propyl-, isopropyl-, butyl-, sec-butyl, and allyl levulinate from moderate to good yield. Performing, in the best-found reaction conditions, five grams scale alcoholysis reactions allowed setting up a purification procedure for all the investigated alkyl levulinates that were recovered in good yield via distillation and fully characterized. Furthermore, recycling tests conducted on the ethanolysis of FA showed that the catalyst and the exceeding ethanol can be recycled up to four times before Purolite CT151 started losing its efficiency. 
These encouraging results may lead the way to future investigation of this catalyst on more complicated substrates, such as monosaccharide (D-Glucose and D-Fructose) and disaccharides (sucrose and cellobiose), eventually also employing a continuous-flow apparatus.

Supplementary Materials: The following are available online at https:/ / www.mdpi.com/article/ 10.3390 / suschem2030027/s1, Figure S1: Examples of the substrate/product degradation observed without previous filtration on basic alumina; Table S1: Purolite physical and chemical characteristics; Table S2: Synthesis of EtLev starting from FA at different temperatures; Table S3: Synthesis of EtLev starting from FA employing different solvent amount; Table S4: Synthesis of EtLev starting from FA: Preliminary investigation for catalyst recycling; Scheme S1: Reaction scheme of EtLev synthesis.

Author Contributions: Conceptualization, F.A.; methodology and investigation, M.A., G.T., and L.L.; writing - original draft preparation, F.A. and M.A.; supervision, F.A. All authors have read and agreed to the published version of the manuscript.

Funding: This research was funded by the Organization for the Prohibition of Chemical Weapons (OPCW), Project Number L/ICA/ICB/218789/19. This article is also within the frame of COST Action FUR4Sustain (CA18220-European network of FURan based chemicals and materials FOR a Sustainable development), supported by COST (European Cooperation in Science and Technology). We want to acknowledge Istituto nazionale della previdenza sociale (INPS) for funding the PhD fellowship of Giacomo Trapasso.

Institutional Review Board Statement: Not applicable.

Informed Consent Statement: Not applicable.

Data Availability Statement: All data supporting this work are reported in the supporting information file.

Acknowledgments: We would like to acknowledge Purolite ${ }^{\circledR}$ (https:/ / www.purolite.com, accessed on 20 July 2021) for providing us with numerous samples of Purolites used in this work.

Conflicts of Interest: The authors declare no conflict of interest.

\section{References}

1. Climent, M.J.; Corma, A.; Iborra, S. Conversion of biomass platform molecules into fuel additives and liquid hydrocarbon fuels. Green Chem. 2014, 16, 516-547. [CrossRef]

2. Zhang, J.; Wu, S.; Li, B.; Zhang, H. Advances in the catalytic production of valuable levulinic acid derivatives. ChemCatChem 2012, 4, 1230-1237. [CrossRef]

3. Liu, X.; Yang, W.; Zhang, Q.; Li, C.; Wu, H. Current approaches to alkyl levulinates via efficient valorization of biomass derivatives. Front. Chem. 2020, 8, 794. [CrossRef]

4. Démolis, A.; Essayem, N.; Rataboul, F. Synthesis and applications of alkyl levulinates. ACS Sustain. Chem. Eng. 2014, 2, 1338-1352. [CrossRef]

5. Christensen, E.; Williams, A.; Paul, S.; Burton, S.; McCormick, R.L. Properties and performance of levulinate esters as diesel blend components. Energy Fuels 2011, 25, 5422-5428. [CrossRef]

6. Jia, S.; Ma, J.; Wang, D.; Wang, K.; Zheng, Q.; Song, C.; Guo, X. Fast and efficient upgrading of levulinic acid into long-chain alkyl levulinate fuel additives with a tungsten salt catalyst at low temperature. Sustain. Energy Fuels 2020, 4, 2018-2025. [CrossRef]

7. Shrivastav, G.; Khan, T.S.; Agarwal, M.; Haider, M.A. Reformulation of gasoline to replace aromatics by biomass-derived alkyl levulinates. ACS Sustain. Chem. Eng. 2017, 5, 7118-7127. [CrossRef]

8. Shao, Y.; Sun, K.; Li, Q.; Liu, Q.; Zhang, S.; Liu, Q.; Hu, G.; Hu, X. Copper-based catalysts with tunable acidic and basic sites for the selective conversion of levulinic acid/ester to gamma-valerolactone or 1,4-pentanediol. Green Chem. 2019, 21, 4499-4511. [CrossRef]

9. Vaccaro, L.; Santoro, S.; Curini, M.; Lanari, D. The emerging use of $\gamma$-valerolactone as a green solvent. Chem. Today 2017, 35, 46-48.

10. Raspolli Galletti, A.M.; Antonetti, C.; Fulignati, S.; Licursi, D. Direct alcoholysis of carbohydrate precursors and real cellulosic biomasses to alkyl levulinates: A critical review. Catalysts 2020, 10, 1221. [CrossRef]

11. Ramírez, E.; Bringué, R.; Fitè, C.; Iborra, M.; Tejero, J.; Cunill, F. Assessment of ion exchange resins as catalysts for the direct transformation of fructose into butyl levulinate. Appl. Catal. A 2021, 612, 117988. [CrossRef]

12. Liu, J.; Yang, B.-B.; Wang, X.-Q.; Liu, C.-L.; Yang, R.-Z.; Dong, W.-S. Glucose conversion to methyl levulinate catalyzed by metal ion-exchanged montmorillonites. Appl. Clay Sci. 2017, 141, 118-124. [CrossRef]

13. Srinivasa Rao, B.; Krishna Kumari, P.; Dhana Lakshmi, D.; Lingaiah, N. One pot selective transformation of biomass derived chemicals towards alkyl levulinates over titanium exchanged heteropoly tungstate catalysts. Cat. Today 2018, 309, $269-275$. 
14. Jiang, L.; Zhou, L.; Chao, J.; Zhao, H.; Lu, T.; Su, Y.; Yang, X.; Xu, J. Direct catalytic conversion of carbohydrates to methyl levulinate: Synergy of solid Brønsted acid and Lewis acid. Appl. Catal. B 2018, 220, 589-596. [CrossRef]

15. Liu, J.; Wang, X.-Q.; Yang, B.-B.; Liu, C.-L.; Xu, C.-L.; Dong, W.-S. Highly efficient conversion of glucose into methyl levulinate catalyzed by tin-exchanged montmorillonite. Renew. Energy 2018, 120, 231-240. [CrossRef]

16. Xu, X.; Zhang, X.; Zou, W.; Yue, H.; Tian, G.; Feng, S. Conversion of carbohydrates to methyl levulinate catalyzed by sulfated montmorillonite. Cat. Commun. 2015, 62, 67-70. [CrossRef]

17. Karnjanakom, S.; Maneechakr, P.; Samart, C.; Kongparakul, S.; Guan, G.; Bayu, S. Direct conversion of sugar into ethyl levulinate catalyzed by selective heterogeneous acid under co-solvent system. Cat. Commun. 2020, 143, 106058. [CrossRef]

18. Heda, J.; Niphadkar, P.; Bokade, V. Efficient synergetic combination of $\mathrm{H}-\mathrm{USY}$ and $\mathrm{SnO}_{2}$ for direct conversion of glucose into ethyl levulinate (biofuel additive). Energy Fuels 2019, 33, 2319-2327. [CrossRef]

19. Tiong, Y.W.; Yap, C.L.; Gan, S.; Yap, W.S.P. Conversion of biomass and its derivatives to levulinic acid and levulinate esters via ionic liquids. Ind. Eng. Chem. Res. 2018, 57, 4749-4766. [CrossRef]

20. Liu, R.; Chen, J.; Huang, X.; Chen, L.; Ma, L.; Li, X. Conversion of fructose into 5-hydroxymethylfurfural and alkyl levulinates catalyzed by sulfonic acid-functionalized carbon materials. Green Chem. 2013, 15, 2895-2903. [CrossRef]

21. Song, D.; Zhang, Q.; Sun, Y.; Zhang, P.; Guo, Y.-H.; Hu, J.-L. Design of ordered mesoporous sulfonic acid functionalized $\mathrm{ZrO}_{2}$ /organosilica bifunctional catalysts for direct catalytic conversion of glucose to ethyl levulinate. ChemCatChem 2018, 10, 4953-4965. [CrossRef]

22. Bart, H.J.; Reidetschlager, J.; Schatka, K.; Lehmann, A. Kinetics of esterification of levulinic acid with n-butanol by homogeneous catalysis. Ind. Eng. Chem. Res. 1994, 33, 21-25. [CrossRef]

23. Melero, J.A.; Morales, G.; Iglesias, J.; Paniagua, M.; Hernandez, B.; Penedo, S. Efficient conversion of levulinic acid into alkyl levulinates catalyzed by sulfonic mesostructured silicas. Appl. Catal. A Gen. 2013, 466, 116-122. [CrossRef]

24. Sankar, E.S.; Mohan, V.; Suresh, M.; Saidulu, G.; Raju, B.D.; Rao, K.S.R. Vapor phase esterification of levulinic acid over $\mathrm{ZrO}_{2} / \mathrm{SBA}-15$ catalyst. Catal. Commun. 2016, 75, 1-5. [CrossRef]

25. Mamman, A.S.; Lee, J.-M.; Kim, Y.-C.; Hwang, I.T.; Park, N.-J.; Hwang, Y.K.; Chang, J.-S.; Hwang, J.-S. Furfural: Hemicellulose/xylose derived biochemical. Biofuels Bioprod. Biorefin. 2008, 2, 438-454. [CrossRef]

26. Huang, Y.-B.; Yang, T.; Zhou, M.-C.; Pan, H.; Fu, Y. Microwave-assisted alcoholysis of furfural alcohol into alkyl levulinates catalyzed by metal salts. Green Chem. 2016, 18, 1516-1523. [CrossRef]

27. Bernal, H.G.; Oldani, C.; Funaioli, T.; Raspolli Galletti, A.M. AQUIVION perfluorosulfonic acid resin for butyl levulinate production from furfuryl alcohol. New J. Chem. 2019, 43, 14694-14700. [CrossRef]

28. Van De Graaf, W.D.; Lange, J.-P. Process for the Conversion of Furfuryl Alcohol into Levulinic Acid or Alkyl Levulinate. U.S. Patent 2007/49771 A1, 4 September 2007.

29. Lange, J.P.; van de Graaf, W.D.; Haan, R.J. Conversion of furfuryl alcohol into ethyl levulinate using solid acid catalysts. ChemSusChem 2009, 2, 437-441. [CrossRef]

30. Jorge, E.Y.C.; Lima, T.D.M.; Lima, C.G.S.; Marchini, L.; Castelblanco, W.N.; Rivera, D.G.; Urquieta-González, E.A.; Varma, R.S.; Paixão, M.W. Metal-exchanged magnetic $\beta$-zeolites: Valorization of lignocellulosic biomass-derived compounds to platform chemicals. Green Chem. 2017, 19, 3856-3868. [CrossRef]

31. Nandiwale, K.Y.; Pande, A.M.; Bokade, V.V. One step synthesis of ethyl levulinate biofuel by ethanolysis of renewable furfuryl alcohol over hierarchical zeolite catalyst. RSC Adv. 2015, 5, 79224-79231. [CrossRef]

32. Zhao, D.; Prinsen, P.; Wang, Y.; Ouyang, W.; Delbecq, F.; Len, C.; Luque, R. Continuous flow alcoholysis of furfuryl alcohol to alkyl levulinates using zeolites. ACS Sustain. Chem. Eng. 2018, 6, 6901-6909. [CrossRef]

33. Li, X.; Li, Y.; Wang, X.; Peng, Q.; Hui, W.; Hu, A.; Wang, H. Zr-DBS with sulfonic group: A green and highly efficient catalyst for alcoholysis of furfuryl alcohol to ethyl levulinate. Catal. Lett. 2021, 151, 2622-2630. [CrossRef]

34. Yogita Rao, B.S.; Subrahmanyam, C.; Lingaiah, N. The selective conversion of furfuryl alcohol to ethyl levulinate over Zr-modified tungstophosphoric acid supported on $\beta$-zeolites. New J. Chem. 2021, 45, 3224-3233. [CrossRef]

35. Tiwari, M.S.; Gawade, A.B.; Yadav, G.D. Magnetically separable sulfated zirconia as highly active acidic catalysts for selective synthesis of ethyl levulinate from furfuryl alcohol. Green Chem. 2017, 19, 963-976. [CrossRef]

36. Siva Sankar, E.; Saidulu, R.; Jyothi, Y.; David Raju, B.; Rama Rao, K.S. Alcoholysis of furfuryl alcohol into n-butyl levulinate over sba-16 supported heteropoly acid catalyst. Catal. Lett. 2017, 147, 2807-2816. [CrossRef]

37. Sun, Y.; Guo, Y.; Song, D.; An, S. Efficient conversion of levulinic acid or furfuryl alcohol into alkyl levulinates catalyzed by heteropoly acid and $\mathrm{ZrO}_{2}$ bifunctionalized organosilica nanotubes. J. Catal. 2016, 333, 184-199.

38. Zhang, Z.; Dong, K.; Zhao, Z. Efficient conversion of furfuryl alcohol into alkyl levulinates catalyzed by an organic-inorganic hybrid solid acid catalyst. ChemSusChem 2011, 4, 112-118. [CrossRef]

39. Dicks, J.S.; Keogh, J.; Manyar, H.G.; Ranade, V.V.; Tiwari, M.S. Direct conversion of furfuryl alcohol to butyl levulinate using tin exchanged tungstophosphoric acid catalysts. Mol. Catal. 2020, 488, 110918.

40. Zhao, G.; Liu, M.; Xia, X.; Li, L.; Xu, B. Conversion of furfuryl alcohol into ethyl levulinate over glucose-derived carbon-based solid acid in ethanol. Molecules 2019, 24, 1881. [CrossRef]

41. Yang, J.; Zhang, H.; Ao, Z.; Zhang, S. Hydrothermal carbon enriched with sulfonic and carboxyl groups as an efficient solid acid catalyst for butanolysis of furfuryl alcohol. Catal. Commun. 2019, 123, 109-113. [CrossRef] 
42. Wang, Y.; Zhao, D.; Triantafyllidis, K.S.; Ouyang, W.; Luque, R.; Len, C. Microwave-assisted catalytic upgrading of bio-based furfuryl alcohol to alkyl levulinate over commercial non-metal activated carbon. Mol. Catal. 2020, 480, 110630. [CrossRef]

43. Song, D.; An, S.; Sun, Y.; Zhang, P.; Guo, Y.; Zhou, D. Ethane-bridged organosilica nanotubes functionalized with arenesulfonic acid and phenyl groups for the efficient conversion of levulinic acid or furfuryl alcohol to ethyl levulinate. ChemCatChem 2016, 8 , 2037-2048. [CrossRef]

44. Chada, R.R.; Koppadi, K.S.; Enumula, S.S.; Kondeboina, M.; Kamaraju, S.R.R.; Burri, D.R. Continuous synthesis of fuel additives alkyl levulinates via alcoholysis of furfuryl alcohol over silica supported metal oxides. Catal. Lett. 2018, 148, 1731-1738. [CrossRef]

45. Lu, B.; An, S.; Song, D.; Su, F.; Yang, X.; Guo, Y. Design of organosulfonic acid functionalized organosilica hollow nanospheres for efficient conversion of furfural alcohol to ethyl levulinate. Green Chem. 2015, 17, 1767-1778. [CrossRef]

46. An, S.; Song, D.; Lu, B.; Yang, X.; Guo, Y.-H. Morphology tailoring of sulfonic acid functionalized organosilica nanohybrids for the synthesis of biomass-derived alkyl levulinates. Chem. Eur. J. 2015, 21, 10786-10798. [CrossRef]

47. Neves, P.; Antunes, M.M.; Russo, P.A.; Abrantes, J.P.; Lima, S.; Fernandes, A.; Pillinger, M.; Rocha, S.M.; Ribeiro, M.F.; Valente, A.A. Production of biomass-derived furanic ethers and levulinate esters using heterogeneous acid catalysts. Green Chem. 2013, 15, 3367-3376. [CrossRef]

48. Kim, J.; Shin, M.; Suh, Y.-W. Etherification of biomass-derived furanyl alcohols with aliphatic alcohols over silica-supported nickel phosphide catalysts: Effect of surplus P species on the acidity. Appl. Catal. A 2020, 603, 117763.

49. Wang, G.; Zhang, Z.; Song, L. Efficient and selective alcoholysis of furfuryl alcohol to alkyl levulinates catalyzed by double $\mathrm{SO}_{3} \mathrm{H}$-functionalized ionic liquids. Green Chem. 2014, 16, 1436-1443. [CrossRef]

50. Hengne, A.M.; Kamble, S.B.; Rode, C.V. Single pot conversion of furfuryl alcohol to levulinic esters and $\gamma$-valerolactone in the presence of sulfonic acid functionalized ILs and metal catalysts. Green Chem. 2013, 15, 2540-2547. [CrossRef]

51. Paniagua, M.; Iglesias, M.; Hernández, L.-A. Catalytic upgrading of furfuryl alcohol to bio-products: Catalysts screening and kinetic analysis. Appl. Catal. A 2017, 537, 74-82. [CrossRef]

52. Liu, X.-F.; Li, H.; Zhang, H.; Pan, H.; Huang, S.; Yang, K.-L.; Yang, S. Efficient conversion of furfuryl alcohol to ethyl levulinate with sulfonic acid-functionalized MIL-101(Cr). RSC Adv. 2016, 6, 90232-90238. [CrossRef]

53. Gupta, S.S.R.; Kantam, M.L. Catalytic conversion of furfuryl alcohol or levulinic acid into alkyl levulinates using a sulfonic acid-functionalized hafnium-based MOF. Catal. Commun. 2019, 124, 62-66. [CrossRef]

54. Zhang, Z.; Yuan, H.; Wang, Y.; Ke, Y. Preparation and characterisation of ordered mesoporous $\mathrm{SO}_{4}{ }^{2-} / \mathrm{Al}_{2} \mathrm{O}_{3}$ and its catalytic activity in the conversion of furfuryl alcohol to ethyl levulinate. J. Solid State Chem. 2019, 280, 120991. [CrossRef]

55. Biancalana, L.; Fulignati, S.; Antonetti, C.; Zacchini, S.; Provinciali, G.; Pampaloni, G.; Raspolli Galletti, A.M.; Marchetti, F. Ruthenium p-cymene complexes with $\alpha$-diimine ligands as catalytic precursors for the transfer hydrogenation of ethyl levulinate to $\gamma$-valerolactone. New J. Chem. 2018, 42, 17574-17586. [CrossRef]

56. Kuo, C.; Poyraz, A.S.; Jin, L.; Meng, Y.; Pahalagedara, L.; Chen, S.; Kriz, D.A.; Guild, C.; Gudz, A.; Suib, S.L. Heterogeneous acidic TiO2 nanoparticles for efficient conversion of biomass derived carbohydrates. Green Chem. 2014, 16, 785-791. [CrossRef]

57. Guo, K.; Huang, J.; Li, A.; Li, Y.; Yang, Z.; Zhang, Z. Photoredox-Catalyzed isomerization of highly substituted allylic alcohols by C-H bond activation. Angew. Chem. 2020, 59, 11660-11668. [CrossRef]

58. Bartoli, G.; Bosco, M.; Carlone, A.; Dalpozzo, R.; Marcantoni, E.; Melchiorre, P.; Sambria, L. Reaction of dicarbonates with carboxylic acids catalyzed by weak lewis acids: General method for the synthesis of anhydrides and esters. Synthesis 2007, 22, 3489-3496. [CrossRef] 